\title{
UM PROGRAMA DE ENSINO PARA A DISCIPLINA FISIOLOGIA VEGETAL
}

\section{Maineide Zanotto Velasques*}

Neste artigo será apresentado um programa de ensino da disciplina Fisiologia Vegetal, sob forma de mapa conceitual. A disciplina Fisiologia Vegetal está inserida na grade curricular do curso de Biologia da UCDB e a execução do trabalho trouxe consigo uma carga de satisfação ao realizá-lo, pois as idéias de totalidade e de inclusividade dos conteúdos ressaltam desde o início do trabalho e durante o seu desenvolvimento, dando uma visão de conjunto para a disciplina e sensação de seu domínio numa única unidade.

A elaboração do programa de ensino da disciplina Fisiologia Vegetal, a partir de mapas conceituais, permitiu algumas observações como a que, na aprendizagem significativa, os conteúdos prévios elaborados pelos alunos é fator essencial, mas a organização lógica do material de aprendizagem favorece também e muito essa aprendizagem; a forma de apresentação em mapa como início ou final da programação torna evidente a rede de

* Professora de Botânica da curso de Biologia da UCDB. Cursa o programa de Mestrado em Educação na UCDB. 
relações, cientificamente, existentes entre os conceitos a serem ensinados e a abordagem que se imprime à matéria; destaque de quais aspectos deveriam ser, inicialmente, premiados a fim de garantir a aprendizagem significativa que consiste na inclusão da nova informação ao conceito já existente.

A elaboração de programa de ensino de uma disciplina tem consistido, até então, em organizar tópicos do conteúdo que permitem, ao final do semestre letivo, o cumprimento da totalidade desses conteúdos. A preocupação maior tem sido a de elencar os conteúdos a serem estudados pelos alunos, de modo a abranger a maior quantidade de assuntos considerados importantes e que sejam fundamentais, no caso, para a formação do professor de Biologia. Esse elenco de conteúdos, na verdade, consiste numa listagem, numa seqüência linear dos tópicos que, mesmo guardando uma relacão entre si, deixam a desejar quanto à apresentação integrada e conjunta. Embora em alguns casos essa interação possa ocorrer, esta não fica facilitada pela organização do conteúdo da disciplina que se torna descritiva, exaustiva, enfadonha, por constituir tópicos isolados.

No entanto, não era considerada de importância expressiva estruturar, logicamente, os conteúdos, pensando em favorecer uma aprendizagem capaz de ligar os conceitos entre si a partir dos fundamentais, de tal forma que, se a ligação não ocorrer, pode-se então dizer que a aprendizagem significativa (a que realmente interessa) não aconteceu ou se pode afirmar que uma maneira mecânica de se aprender tenha acontecido, daí que ela estaria fadada a um esquecimento muito em breve, pois que na vida cotidiana 
do aluno não teria importância, ao mesmo tempo que ele não se utilizaria deles para resolver problemas diários, apesar de serem base para a resolução.

Com a proposta de elaboração de programa de qualquer disciplina, a partir do modelo de ensino proposto por David Ausubel, em que a alguns conceitos básicos se prendem os intermediários e os específicos, tem-se uma alternativa para facilitar a aprendizagem significativa. A forma de programação tem que ser repensada e, portanto, os programas, remodelados de modo a expressar a estrutura lógica do conhecimento, a mesma a ser incorporada e elaborada pela estrutura psicológica do aluno.

Ao elaborar o mapa conceitual diagrama que expressa as relações entre os conceitos a partir do mais geral(ais) ao mais específico(s) da disciplina Fisiologia Vegetal, ficou claro que conceitos significativos de Citologia e Anatomia Vegetais já tivessem sido, previamente, formados. Os conceitos mais significativos dentro da disciplina deveriam ser trabalhados por serem fundamentais, juntamente com a relação existente entre eles por lhes imprimir articulação.

Caso os conceitos prévios (das disciplinas anteriores) não tenham sido plenamente elaborados, indicam que esse é o caminho a ser tomado, de tal forma que ao se iniciarem os conteúdos da disciplina, esses organizadores sejam retomados para servir ou de ponte para os novos conteúdos, ou de subsídio para os mesmos.

A formulação de um corpo de conhecimentos, a partir dos grandes conceitos facilitadores, possibilitou 


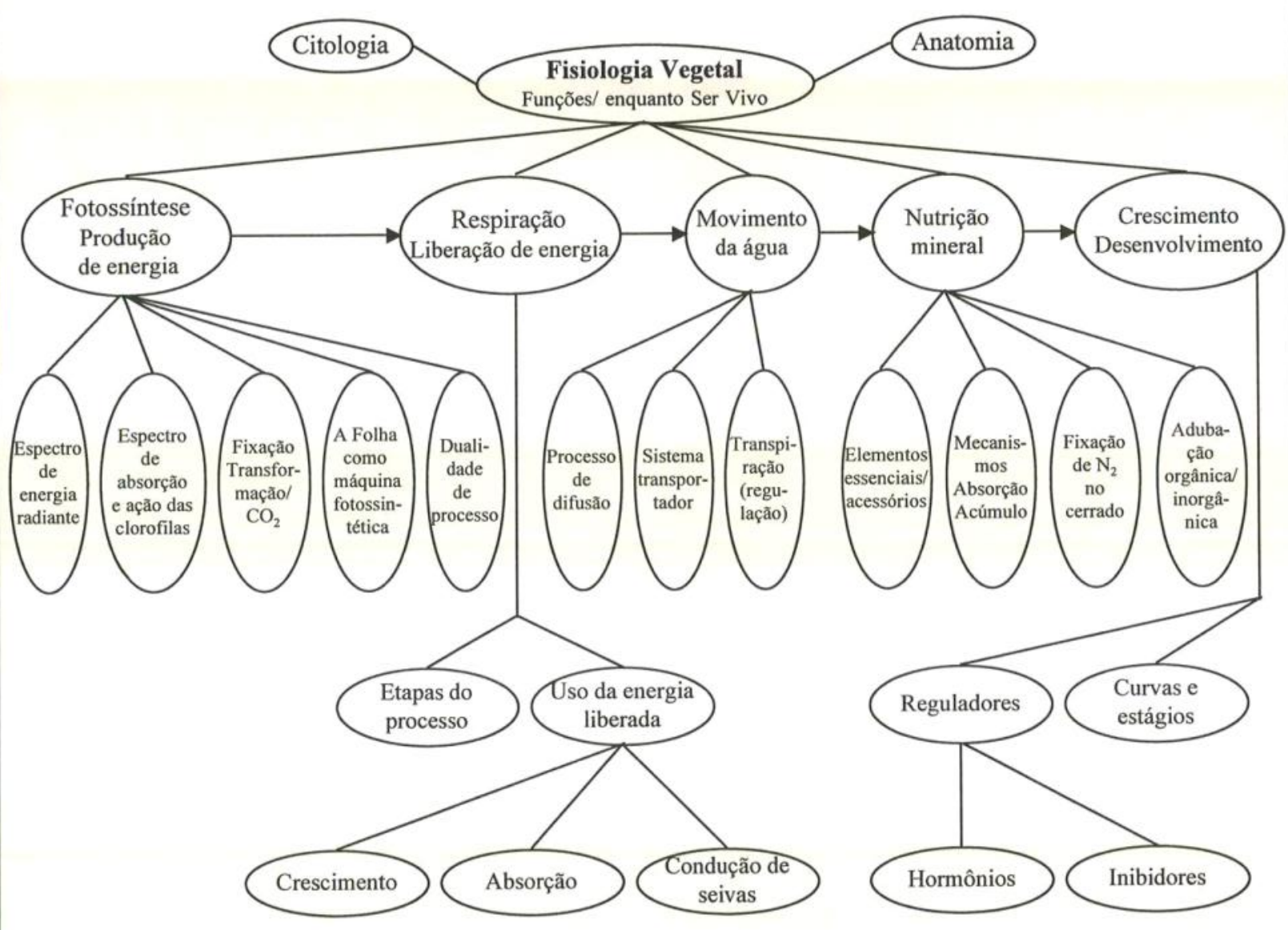

Fig. 1 : Mapa Conceitual da disciplina Fisiologia Vegetal (Curso de Biologia da UCDB) 
relacionar os conteúdos novos a serem assimilados aos já conhecidos, encurtando alguns passos nesse processo de aprendizagem.

Outra observação feita foi a lógica na seqüência da apresentação dos tópicos do programa, de tal forma articulados, propiciando uma imagem globalizante e interrelacionada que, de outra maneira, não garantiria a efetiva aprendizagem.

A estrutura organizada da disciplina, visualizada pelo mapa conceitual, facilita a realização de interações que ocorrerão no processo instrucional durante $o$ ano letivo. As mesmas interações poderiam até existir quando da apresentação do programa linear, mas nunca se apresentariam evidentes, nem permitiriam que as mesmas relações de progressividade e integridade fossem claramente notadas.

A retenção de um conteúdo ocorre, mais eficientemente, se este for apresentado de forma clara, organizada. É importante para o aluno partir de uma visão geral, abrangente para se fixar depois nos detalhes, e o quanto é importante para o professor e aluno utilizarem-se de um dado conceito prévio para se conseguir estruturar um novo.

Outro detalhe importante é a necessidade de que as disciplinas trabalhem de forma engajadas que se sirvam de mesmas estruturas, conceitos e garantam, assim, uma formação mais eficaz dos nossos alunos. A utilização dos conceitos prévios organizados em outras disciplinas mostram isso.

A aprendizagem significativa implica na apreensão 
de informações, idéias, conceitos alinhados de maneira clara e disponíveis na estrutura cognitiva do aluno e sirvam sempre de suporte a novos conceitos e informações.

Adequar a estrutura da disciplina ensinada à estrutura cognitiva do aluno facilita a aprendizagem. Por consegüinte, a nova estruturação do programa da disciplina Fisiologia Vegetal busca facilitar essa aprendizagem.

A contribuição do mapa conceitual na organização, elaboração do programa,bem como na execução do trabalho de uma disciplina, mostra sua validade e sua atual utilização, e tem nos mostrado sua eficiência.

\section{REFERÊNCIAS BIBLIOGRÁFICAS}

MOREIRA, M.A. e BUCHWEITZ, B. Mapas conceituais. São Paulo : Ed. Moraes, 1987. 